\title{
Optimization and Validation of Analytical Method for Determination of Histamine in Fish using HPLC-FLD
}

\author{
Ahmed A. Ghazi ${ }^{1 *}$, Magdy M. Mohamed ${ }^{2}$, Sohair A Gad Alla ${ }^{1}$, Glenn Kennedy ${ }^{3}$ and Emad R. Atalla ${ }^{1}$ \\ ${ }^{l}$ Central Lab of Residue Analysis of Pesticides and Heavy Metals in Food, Agriculture Research Center, Dokki, Giza \\ 12311, Cairo, Egypt, \\ ${ }^{2}$ Department of Biochemistry, Faculty of Science, Ain Shams University, Cairo, Egypt, \\ ${ }^{3}$ Veterinary science division, Agri-food and biosciences institutes, Northern Ireland-UK
}

A R T I C L E I N F O

Article history:

Received 01 July 2015

Accepted 29 July 2015

Keywords:

Histamine;

HPLC- FLD;

Fish;

Validation.

\begin{abstract}
A B S T R A C T
In the present study, simple and reliable method of histamine analysis was developed, optimized and validated to meet the requirements of fish safety. Histamine in fish samples was extracted with a methanol-phosphate buffer including $2 \%$ TCA solution (50:50, v/v) followed by defatting with hexane after centrifugation at 13,000 rpm. Histamine was separated, identified by reversed phase high performance liquid chromatography (HPLC) with gradient mobile phase (methanol-phosphate buffer at $\mathrm{pH}$ 3.5) and quantified by fluorescence detector at excitation: $345 \mathrm{~nm}$, emission: $445 \mathrm{~nm}$ after on-line derivatization with O-phathalaldehyde in a pre-column derivatization step using automatic injection program. The method was validated with average recovery $96 \%$ and coefficient of variation $(\mathrm{CV} \%)$ less than $8 \%$. The uncertainty was estimated and was set to $\pm 26.4 \%$. The performance of the proposed method was checked with a sample from the Food Analysis Performance Assessment Scheme (FAPAS) as an external quality control; the z-score was found within acceptable range $|Z|<2$. Thirty four fish samples were subjected to histamine assessment using the validated method. Only one sample was contaminated with histamine and exceeding the permissible limit set by Codex Alimentarious.
\end{abstract}

\section{Introduction}

Histamine is a biogenic amine generated post-mortem in fish and certain fish-based products due to product mishandling, bad storage and abuse. Free histidine found in abundance in the muscle of certain fish (most notably tunas, mahi mahi, and mackerel) is converted enzymatically by some spoilage bacteria to histamine ${ }^{[1]}$ which causes the allergy-like symptoms of scombroid poisoning. Scombroid poisoning ranks among the most problematic chemical intoxications from seafood ${ }^{[2]}$. The name "scombroid poisoning" was coined because histamine ("scombrotoxin") is produced in fish species of the families Scombridae and Scomberesocidae, as well as some non-scombroid fish like Coryphaena and Pomatomus.

Therefore, the presence of histamine is of great importance when evaluating food toxicity; it has also been proposed as an indicator of hygienic quality ${ }^{[3]}$. It is worthy to mention that there is also evidence of linkaging elevated biogenic amine levels and cancer ${ }^{[4]}$.

\footnotetext{
* Corresponding author.

E-mail address: aabghazi@yahoo.com
}

High concentrations of polyamines have been observed in breast and colon cancer cells ${ }^{[5]}$. The detection and prevention of histamine in fish have been identified by the Food and Drug Administration as an important component of Hazard Analysis Critical Control Point (HACCP) ${ }^{[6]}$. It assessed that, good-quality fish should contain less than $10 \mathrm{mg} / \mathrm{kg}$ of histamine, whereas a level of $30 \mathrm{mg} / \mathrm{kg}$ indicates significant deterioration and 50 $\mathrm{mg} / \mathrm{kg}$ is considered to be a conclusive evidence of decomposition; fish with this level or greater should not be sold for human consumption ${ }^{[7]}$. Currently, histamine is the only biogenic amine (BA) having official limits in fish products. Histamine is regulated as $50 \mathrm{mg} / \mathrm{kg}$ by the US Food and Drug Administration ${ }^{[8]}$ and as $100 \mathrm{mg} / \mathrm{kg}$ by the European Community ${ }^{[9]}$ and Codex Alimentarius [10].

Estimation of histamine in foods is desirable because of its potentially toxic effects and also because it can be used as indicator of food freshness and spoilage during transportation especially when exporting to another countries. Several analytical methods for the determination of biogenic amines in foods have been 
described. These include thin layer chromatography ${ }^{[11]}$, biosensors ${ }^{[12]}$, capillary electrophoresis ${ }^{[13]}$ and reversed phase high performance liquid chromatography (HPLC) 4, 14-16]. Positive confirmation using mass spectrometry either after HPLC ${ }^{[17,18]}$ or gas chromatographic separation [19] has also been reported. Of these techniques, HPLC is the most frequently reported for the separation and quantification of biogenic amines because of its high sensitivity and wide range of linearity ${ }^{[20]}$. The objective of this study to establish a rapid, sensitive, and reproducible analytical method for quantification of histamine in fish and fish products to access their compliance to the established standards before consuming locally or exporting to other countries. The developed method will be validated in terms of sensitivity, repeatability, linearity, accuracy, and precision. The applicability of the developed method for the routine monitoring of locally produced or exported fish will be investigated, as part of the national monitoring program for food contaminates in Egyptian food of animal origin. This should help various Egyptian exporters to penetrate international markets.

\section{Materials and methods}

\section{Samples collection and processing}

Fish samples were purchased from local markets in Egypt and analyzed using the developed method. The type and the number of analyzed samples were shown in Table 1. Samples were immediately frozen to reduce formation of histamine during transport and kept at -20 ${ }^{\circ} \mathrm{C}$ not more than 2 days till sample treatment and analysis. Before analysis, fish were partially thawed at room temperature where the edible part was separated and muscle tissue was homogenized well and taken for analysis. Preparation of sampling was taken place according to ${ }^{[21]}$. A total of thirty four fish samples and 16 canned tuna samples were assessed for presence of histamine by using the proposed validated method.

\section{Chemicals, reagents and standard solutions}

- Standard histamine dihydrochloride, was purchased from Merck $99 \%$ purity, O-Phathalaldehyde (Flouka, $\geq 99 \%$ ), 2-Mercaptoethanol (Aldrich,98\%). Methanol and n-Hexane (Lab-scan) (HPLC), assay $>$ 99\%., De-ionized Water generated by Milli-Q.

- Histamine Stock solution $1000 \mathrm{ug} / \mathrm{ml}$ was prepared in $0.1 \mathrm{~N} \mathrm{HCL}$ and stored at $4 \mathrm{C}^{\circ}$ for maximum two years. Intermediate solution of $100 \mathrm{ug} / \mathrm{ml}$ was prepared in methanol / water $(1: 1 \mathrm{v} / \mathrm{v})$ and stored at $4 \mathrm{C}^{\circ}$ not longer than 6 months. A series of calibration solutions of $0.5,1,2,5,10$ and $25 \mathrm{ug} / \mathrm{ml}$ was prepared from intermediate standard solution $(100 \mathrm{ug} / \mathrm{ml})$ by dilution of $0.05,0.1,0.2,0.5,1.0$ and $2.5 \mathrm{ml}$ respectively. It was prepared in $10 \mathrm{ml}$ flask using extraction solution. The calibration solutions was kept also at $4 \pm 2 \mathrm{C}^{\mathrm{o}}$ and covered by aluminum foil to avoid degradation. This solution will be used up to three months.

- Orthophosphoric acid (Riedel-deHaen, $\geq 85 \%$ ), $1 \mathrm{M}$ solution prepared.

- 0.1 N HCL; prepared from hydrochloric acid
(Riedel-deHaen, $\geq 33 \%$ ).

- Potasium dihydrogen phosphate (Riedel-deHaen, $\geq 99 \%$ ); $100 \mathrm{mM}$ and $10 \mathrm{mM}$ were prepared by dissolving $13.91 \mathrm{~g}$ and 0.139 in $1000 \mathrm{ml}$ deionised water respectively and adjusted to $\mathrm{pH} 3.5 \pm 0.1$ using $1 \mathrm{M}$ phosphoric acid. These solutions were used as an extraction solution mixture and as a mobile phase $B$ respectivelly.

- Trichloroacetic acid (TCA) 98\%, used to prepare $2 \%$ solution, (dissolve $20 \mathrm{~g}$ in pot. dihydrogen phosphate $100 \mathrm{mM}$ to have an aqueous extraction solution.

- Sodium hydroxide (Riedel-deHaen, $\geq 99 \%$ ); used to prepare $10 \mathrm{M}$ solution (dissolve $40 \mathrm{~g}$ in $100 \mathrm{ml}$ deionised water).

- Sodium borohydride decahydrate (sigma-aldrich $\geq$ $98 \%$ ) used to prepare $10 \mathrm{mM}$, by dissolving $0.382 \mathrm{~g}$ in $100 \mathrm{ml}$ de-ionized water, adjusted to $\mathrm{pH} 10.0$ by $10 \mathrm{M}$ Sod. hydroxide, complete to mark with deionised water.

- Extraction solution, an aqueous extraction solution was mixed with methanol with ratio (1:1).

- Derivatizing Agent: $25 \mathrm{mg}$ OPA dissolved in $1 \mathrm{~mL}$ methanol and $100 \mathrm{ul}$ of 2-mercaptoethanol and complete to $10 \mathrm{~mL}$ by sodium borate buffer; All solutions were stored in brown glass bottles and kept at $4^{\circ} \mathrm{C}$ to be stable for up to three months.

Apparatus and chromatographic conditions

- Ika® T 25 ultra-turrax ${ }^{\circledR}$ homogenizer, Thermoscientific biofuge centrifuge, analytical balance, micropipette of 100-1000 ul and polypropylene tubes of $15 \& 50 \mathrm{ml}$.

- Quantitative analysis was performed using the High performance liquid chromatography HLPC Agilent system, HP 1100 series equipped with Quaternary pump (G1311A), Vacuum degasser (G1322), Auto sampler (G1313). HPLC equipped with fluorescence detector agilent 1100 series (G1321A). Separation was performed on agilent Zorbax XDB C18, 5um $\times$ $150 \times 3.5 \mathrm{~mm}$ column. Software: Chemistation for LC, Rev. A. 09.03 [1417].

- Quantification was carried out by fluorescence detector at $345 \mathrm{~nm}$ (excitation wavelength, Kex) and at 445 (emission wavelength, Kem) with a frequency of $55 \mathrm{~Hz}$ and PMT gain 11. The flow rate of HPLCpump is $0.5 \mathrm{ml} / \mathrm{min}$.

- The elution condition using a gradient mode and mobile phase (A) of methanol and mobile phase (B) of $10 \mathrm{mM}$ phosphate buffer $\mathrm{pH} 3.5 \pm 0.1$, the injection volume is $3 \mathrm{ul}$, and the injection program included 7 lines as shown in Tables 2 and 3 respectively.

Method of analysis

Preparation of fish samples for histamine extraction

- A test portion of $5.0 \mathrm{~g}$ homogenized fish was weighed in $50 \mathrm{ml}$ plastic tube, for spiking tests; use samples that previously analyzed and proved to be histamine free. Extraction solution of $20 \mathrm{ml}$ was added and thoroughly homogenize for 2-3 min using Ultra-Turrax followed by shaking for 1 minute. The 
homogenate was placed in water bath at $60 \pm 5^{\circ} \mathrm{C}$ for half an hour and then centrifuged using UltraCentrifuge at $13,000 \mathrm{rpm}$ for $10 \mathrm{~min}$ at $4^{\circ} \mathrm{C}$. The supernatant was filtered in $50 \mathrm{ml}$ measuring flask through funnel fitted with filter paper Whatman No. $40 \mathrm{~mm}$.

- The extraction step was repeated once again with another $20 \mathrm{ml}$. extraction solution followed by shaking for $1 \mathrm{~min}$, centrifugation carried out as described previously, the supernatant combined at the same $50 \mathrm{ml}$ measuring flask and completed to mark with the extraction solution and shaked well.

- An aliquot of $5 \mathrm{ml}$ was taken into another $15 \mathrm{ml}$ plastic tube and centrifuged at 13,000 rpm for $5 \mathrm{~min}$ with $5 \mathrm{ml} \mathrm{n.Hexane.} \mathrm{The} \mathrm{extract} \mathrm{from} \mathrm{the} \mathrm{lower}$ layer was filtered using disposable acrodisc $0.45 \mathrm{um}$ coupled with $5 \mathrm{ml}$ plastic syringe in HPLC vial.

- $3 \mu$ l of the aqueous layer was subjected to HPLC analysis after online derivatization with OPhathaldehyde in a pre-column derivatization step using automatic injection program. Reagent blank (solvent and reagent) and blank sample (free histamine sample) were analyzed with each set of samples.

- Calibration standard curve was used for the quantification of histamine in samples (peak height VS standard concentration).

\section{Calculations:}

The histamine concentration in sample $\mathrm{Cs}(\mathrm{mg} / \mathrm{kg})$ is calculated as following:

$$
C s=\frac{V f}{W} \times \frac{h_{s a m}}{h_{s t}} \times Y
$$

$\mathrm{C}_{\mathrm{S}}=$ sample concentration $(u g / \mathrm{g})$,

$\mathrm{V}_{\mathrm{f}}=$ final volume $(\mathrm{ml})$,

$\mathrm{A}_{\mathrm{sam}}=$ the height of sample peak,

$\mathrm{A}_{\mathrm{st}}=$ the height of standard in matrix peak,

$\mathrm{Y}=$ standard concentration $(u g / \mathrm{ml})$,

$\mathrm{W}=$ weight of sample $(\mathrm{g})$.
In case: $\mathrm{V}_{\mathrm{f}}=50 \mathrm{ml}, \mathrm{W}=5 \mathrm{~g}$; the calculation formula can be expressed as follows:

$$
C s=10 \times \frac{h_{\text {sam }}}{h_{s t}} \times Y
$$

\section{Validation and Quality Assurance}

The analytical method and instrument were fully validated as part of the quality assurance system in Central Lab. of Residue Analysis of Pesticides and Heavy Metals in Food and accredited by FINAS, Center for Metrology and Accreditation - Finland, according to (ISO / IEC 17025, 2005). The criteria of quality assurance of Codex Committee are followed to determine the performance of the analytical method. Validation of method included; recovery percentages, precision, accuracy, limit of quantification and uncertainty of measurements were carried out for histamine using fish and tuna samples in accordance with the international guidelines.

\section{Results and discussion}

\section{Method development}

Determination of histamine in fish and fishery products are challenging for researchers due to the high matrix contents which interfere with chromatographic peaks of histamine. In the present study, many trials were done to develop simple, reproducible and matrix independent method of analysis. The published method [22] was selected to be developed and optimized.

\section{HPLC separation conditions}

Different mobile phases at different flow rates were tested for HPLC separation. The combination of the mobile phase of methanol (A) / water at $\mathrm{pH} 3.5(\mathrm{~B})$ and methanol (A)/ phosphate buffer at $\mathrm{pH} 3.5(\mathrm{~B})$ was tested with gradient elution. Good resolution was obtained at run time less than 15 min with methanol $(\mathrm{A}) /$ phosphate buffer at $\mathrm{pH} 3.5(\mathrm{~B})$ with gradient elution program as shown in Table 2.

Table 1: The number of fish samples, their types subjected to histamine analysis.

\begin{tabular}{|c|c|c|}
\hline Fish & Species & No. \\
\hline Nile Tilapia & Oreochromis niloticus niloticus & 12 \\
\hline Nile Perch & Lates niloticus & 6 \\
\hline Gilthhead Sea Bream & Sparus auratus & 8 \\
\hline Tilapia gallilly & Sarotherodon galilaeus & 2 \\
\hline Tilapia Zillii & Tilapia zilli & 1 \\
\hline Cat fish & Clarias spp & 3 \\
\hline Blue fish & Pomatomus saltatrix & 2 \\
\hline Total no of fresh water fish & $\mathbf{3 4}$ & \\
\hline Total no of Canned tuna & $\mathbf{1 6}$ & \\
\hline
\end{tabular}


Table 2: HPLC pump settings.

\begin{tabular}{|c|c|c|c|c|}
\hline Step & Time (min) & $\begin{array}{c}\text { Flow rate } \\
(\mathbf{m l} / \mathbf{m i n})\end{array}$ & $\mathbf{A}(\boldsymbol{\%})$ & $\mathbf{B}(\boldsymbol{\%})$ \\
\hline $\mathbf{0}$ & 0 & 0.5 & 0.0 & 100 \\
\hline $\mathbf{1}$ & 3 & 0.5 & 40 & 60 \\
\hline $\mathbf{2}$ & 7 & 0.5 & 60 & 40 \\
\hline $\mathbf{3}$ & 10 & 0.5 & 80 & 20 \\
\hline $\mathbf{4}$ & 15 & 0.5 & 100 & 0.0 \\
\hline
\end{tabular}

Table 3: Injection program for histamine detection using on - line column dereivatization with OPA.

\begin{tabular}{|c|c|}
\hline Steps & Program Command \\
\hline $\mathbf{1}$ & DRAW $5 \mu$ l from vial1,max speed \\
\hline $\mathbf{2}$ & NEEDLE wash in vial 25,3 times \\
\hline $\mathbf{3}$ & DRAW $3 \mu$ l from sample, max speed \\
\hline $\mathbf{4}$ & NEEDLE wash in vial 21,3 times \\
\hline $\mathbf{5}$ & DRAW $5 \mu$ l from vial1, max speed \\
\hline $\mathbf{6}$ & MIX max amount in air, max speed,3 times \\
\hline $\mathbf{7}$ & INJECT \\
\hline
\end{tabular}

On-line dereivatization with O-phathaldehyde (OPA) Histamine has weak chromophore and its sensitivity with UV detector is not as good as with fluorescence detector after derivatisation with OPA with 2mercaptoethanol as reported in ${ }^{[23,24]}$. Low stability of derivatized product was observed and decomposed rapidly that will lead to low reproducibility. In this study, on-site pre-column derivatization program was optimized to eliminate the sensitivity loss with time and enhance the accuracy of injection from one sample to another. The optimized program is described in Table 3. The washing steps in that program are very important to eliminate any cross contamination that could happen during sample injection.

\section{Selection of extraction solvent:}

More than one extraction solvents were examined such as: methanol -phosphate buffer (1:1) at $\mathrm{pH} 3.5$, methanol - phosphate buffer (1:1) at $\mathrm{pH}$, methanol - phosphate buffer (1:1) at $\mathrm{pH} 5$ and methanol - phosphate buffer (1:1) at $\mathrm{pH} 3.5$ combined with $2 \%$ TCA. The last one was selected for method validation because TCA has a role to precipitate proteins and decrease the chromatographic. Figure 1 shows typical chromatograms for histamine standard $(1 \mathrm{ug} / \mathrm{ml})$, blank sample, spike sample $(100$ $u g / \mathrm{g})$ and real contaminated sample (22ug/g) monitored by fluorescence detector at optimized HPLC conditions. The elimination of unwanted peaks that interfere with the analyte of interest is very important. Fats and proteins are most interfered peaks that affect the resolution and accuracy of histamine peak. In this study we use $2 \%$ TCA which agreed with ${ }^{[25]}$ to eliminate proteins effect. n-hexane also added to eliminate fats that predominantly found in fish and tuna samples. This makes the developed procedure easy for apply and cheap rather than using expensive cartridge that reported in the reference such as Oasis Matrix Cation Exchange (MCX) on a Supelco solid phase extraction apparatus (SPE) or STRATA X cartridge as reported ${ }^{[25]}$ which could give us low recoveries due to high methanol content. A series of frequently used cartridges such as C18, HLB were used, but only less than $50 \%$ recoveries could be achieved. This may be attributed to the high methanol content $(50 \%, v / v)$ in the extract solutions ${ }^{[22]}$. Further clean-up was applied when using Thermo Scientific biofuge centrifuge at $13,000 \mathrm{rpm}$ for $10 \mathrm{~min}$ at $5 \mathrm{C}^{\circ}$ to purify the sample before introduced to HPLC.

\section{Matrix effect}

To assess the impact of the fish tissue matrix on standard calibration curve responses for histamine, a calibration graph (the peak height versus standard concentration) was constructed for 5 concentration levels. The concentration levels were $0.5,1,2,5$, and $10 u g / g$ fish for histamine. The matrix effect was checked by comparing the signal ratio between (A) standard prepared in methanol: water $(1: 1 \mathrm{v} / \mathrm{v})$ and (B) standards prepared in the extraction solvents (methanol/phosphate buffer at $\mathrm{pH}$ 3.5 with $2 \%$ TCA) and (C) standard prepared in the matrix of fish extract. It was found that no big difference between (B and $\mathrm{C}$ ) which was less than 15\% difference in signals because the $\mathrm{pH}$ is matched together, while it was 
in big difference between (B or C) and (A) which was more than $50 \%$ higher than obtained with $\mathrm{B}$ or $\mathrm{C}$. This is due to big difference in $\mathrm{pH}$ of methanol/water solution (pH 6) than those of phosphate/buffer with 2\% TCA extraction solution (adjusted at $\mathrm{pH}$ 3.5) which has quenched the signal down. This finding is agreed with [26,27] where they reported that is no need to prepare standards in matrix of fish. Thereby the method procedure is built on preparation of calibration standards in the sample extraction solvent to make $\mathrm{pH}$ is matching between calibration standards and samples extracts and in turn make the procedure easier with no extra work.

\section{Standard stability}

During method development, the standards were checked for stability duration, it was found that histamine stock standard is stable if stored in fridge at 4 ${ }^{\circ} \mathrm{C}$ in dark place for two years as found in the literature, while calibration solutions was checked after three months and found there is no significant loss. During three months, the signals of $10 \mathrm{mg} / \mathrm{l}$ calibration standard were collected and it showed statistically that relative standard deviation was $13 \%$ after online deivatisation with OPA which was agreed with ${ }^{[22,24,27]}$. Figure 2 represents the plotting of standard signals against the concentration of standard $10 \mathrm{ug} / \mathrm{ml}$.

\section{Method validation}

After method development and optimization of different parameters, the method must be tested to prove the "Fitness for Purpose" through a process called method validation. Many international standards were published to discuss different method validation parameters; ${ }^{[28-30]}$ were followed in performing the different validation parameters and uncertainty estimation. The obtained validation results described as follows. Validation of analysis included linearity, limit of detection (LOD), limit of quantification (LOQ), recovery, precision (repeatability and reproducibility) and accuracy.
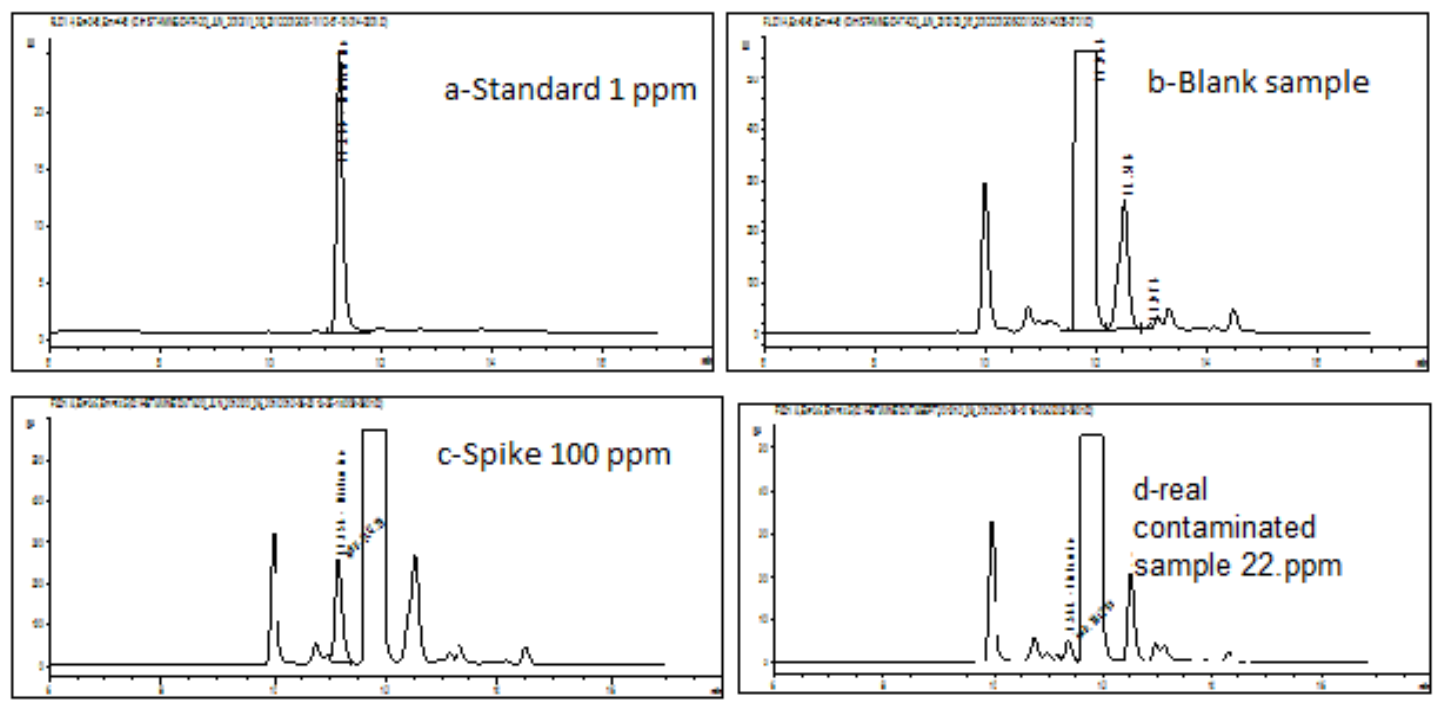

Fig. 1: Typical histamine chromatograms under optimized conditions of HPLC; (a) standard 1 (ug/mL), (b) blank sample, (c) spike sample $100(\mathrm{ug} / \mathrm{g})$ and (d) real contaminated sample 22(ug/g).

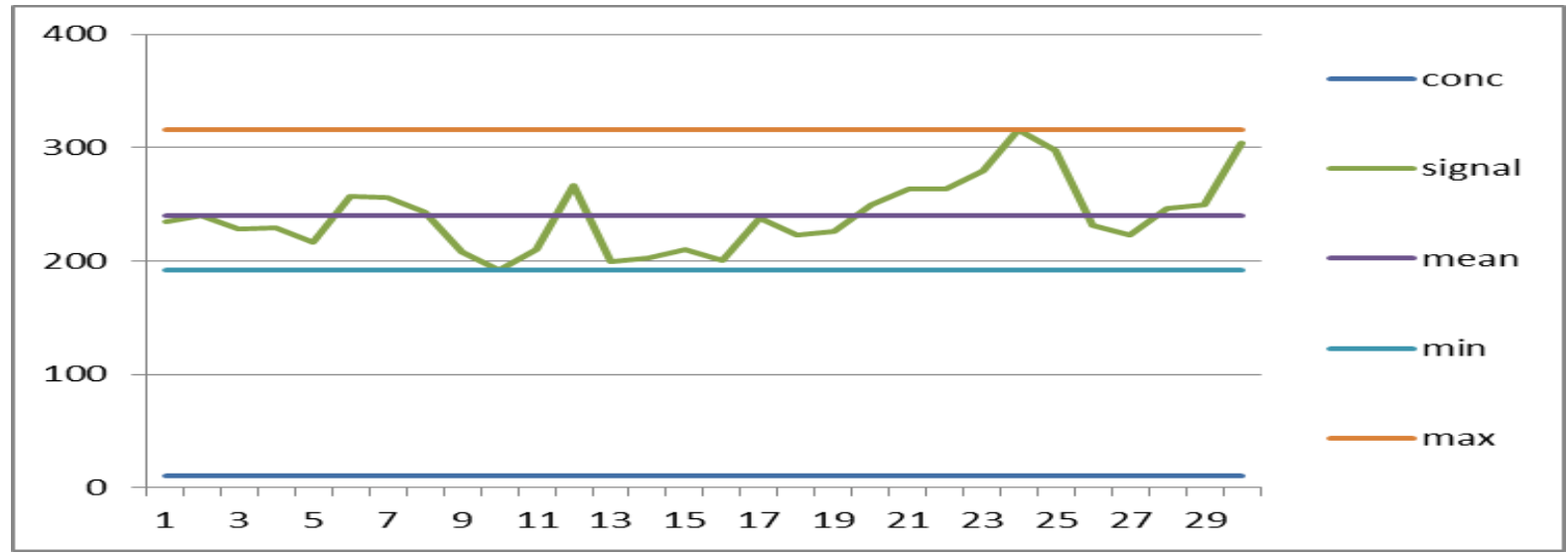

Fig. 2: The signals stability of derivatized standard $10(\mathrm{ug} / \mathrm{ml})$ for 3 months. 


\section{Linear range and calibration curve}

A series of 5 concentrations of histamine calibration solution, in range of 0.5 to $25 \mathrm{ug} / \mathrm{ml}$ were prepared and injected in HPLC-FLD under the described condition to test the linearity of calibration curve. A linear curve was found between peak area and analyte concentration with a good correlation coefficient $\left(R^{2} \geq 0.999\right)$. Calibration was done with each set of injected samples; the linear calibration curve was shown in Figure 3.

Method linearity was tested by performing recovery tests at different four levels of 10, 50, 100 and $200 u g / g$ on fish and tuna samples. The method was found to be linear from the limit of quantitation $10 \mathrm{ug} / \mathrm{g}$ up to 200 $u g / \mathrm{g}$ fish as shown in Figure 4 with correlation coefficient 0.999 .

\section{Sensitivity (LOD and LOQ)}

The results obtained in the linearity test were analyzed to calculate LOD and LOQ. The LOD and LOQ values were calculated using the following equation:

$$
\mathrm{C}=\mathrm{SD} \times \mathrm{S} / \mathrm{K}
$$

Where, SD is the standard deviation of the Y-intercept values, and $\mathrm{K}$ is the mean slope value from the five calibration curves constructed ${ }^{[31]}$. S values were $2 \mathrm{ug} / \mathrm{g}$ for LOD and $10 \mathrm{ug} / \mathrm{g}$ for LOQ, respectively ${ }^{[32,33]}$. The LOD, defined as the smallest concentration from which it is possible to detect the presence of the analyte with reasonable statistical certainty and the LOQ, defined as the lowest concentration of the identified analyte in a sample that can be quantified with acceptable precision and accuracy. The sensitivity of the method as reflected by the LOD and LOQ values was 1.5 and $5 \mathrm{ug} / \mathrm{g}$ similar to those reported in the literature ${ }^{[16,17,34]}$.

\section{Recovery tests}

The recovery tests for histamine were performed by using repeated spike samples on fish and tuna samples at different concentration levels. The average recoveries and relative standard deviation on each level were calculated. The obtained mean recovery $\%$ ranged between $90-102$ $\%$ with $\mathrm{CV} \%$ of less than $6 \%$ for fish and $7 \%$ for tuna sample respectively, as shown in Table 4.

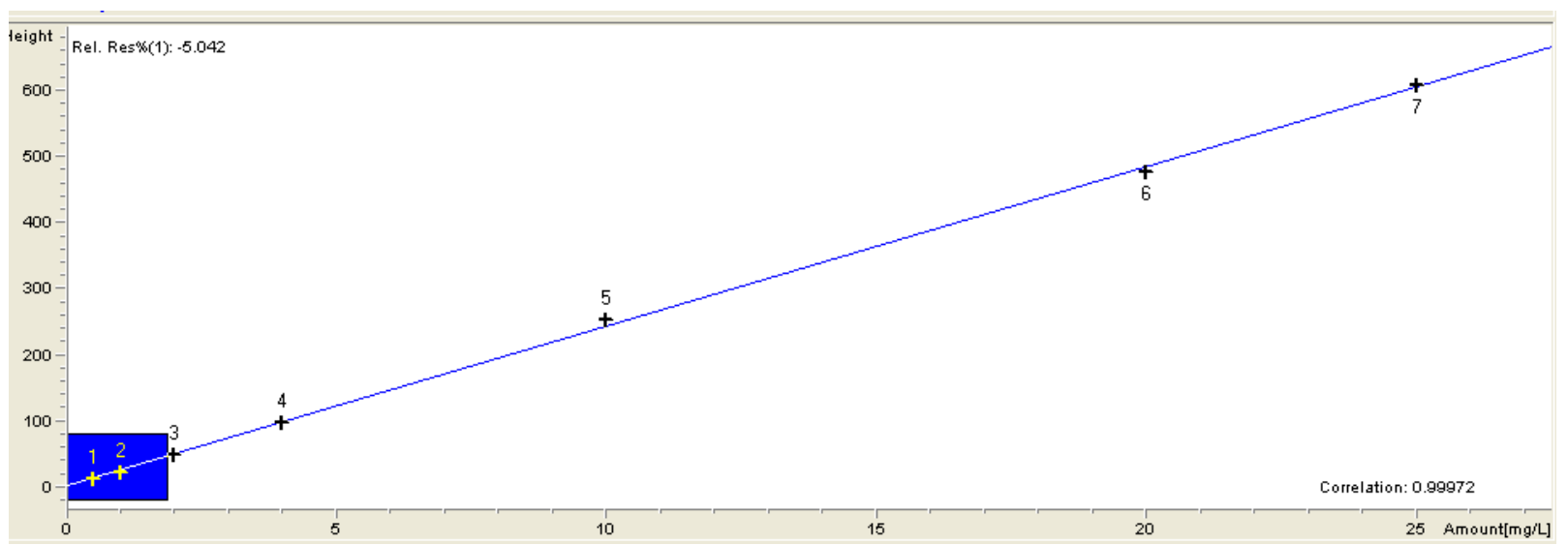

Fig. 3: Histamine standards calibration curve from 0.5 up to $25 \mathrm{ug} / \mathrm{ml}, \mathrm{R} 2=0.99972$.

\begin{tabular}{|c|c|c|c|c|}
\hline no. & $\begin{array}{c}\text { Expected } \\
(\mathbf{u g} / \mathbf{g})\end{array}$ & $\begin{array}{c}\text { Mean } \\
\text { found }(\mathbf{u g} / \mathbf{g}) \\
\mathbf{n = 6}\end{array}$ & $\begin{array}{c}\text { Mean } \\
\text { recovery } \\
\mathbf{\%}\end{array}$ \\
\hline 1 & 10 & 9 & 90 \\
\hline 2 & 50 & 49 & 98 \\
\hline 3 & 100 & 102 & 102 \\
\hline & 200 & 192 & 96 & \\
\hline & Correlation $=$ & $\mathbf{0 . 9 9 9}$ & & \\
\hline
\end{tabular}

Fig. 4: Linearity of the method at different four levels on fish samples. 
Table 4: Recovery tests at different concentration levels on fish and tuna samples.

\begin{tabular}{|c|c|c|c|c|c|c|c|c|}
\hline \multirow{2}{*}{$\begin{array}{c}\text { Spiked } \\
\text { conc. } \\
(\mathbf{m g} / \mathbf{L})\end{array}$} & \multicolumn{2}{|c|}{$\begin{array}{c}\text { Found } \\
\text { Concentration } \\
(\mathbf{m g} / \mathbf{k g})\end{array}$} & \multicolumn{2}{c|}{$\begin{array}{c}\text { Mean recovery } \\
\text { \% } \mathbf{\pm} \text { Sd } \\
(\mathbf{n = 6})\end{array}$} & \multicolumn{2}{c|}{$\begin{array}{c}\text { Precision\% as } \\
\text { (CV \%) }\end{array}$} & \multicolumn{2}{|c|}{$\begin{array}{c}\text { Accuracy\% as } \\
\text { (Bias) }\end{array}$} \\
\cline { 2 - 9 } & Fish & Tuna & Fish & Tuna & Fish & Tuna & Fish & Tuna \\
\hline $\mathbf{1 0}$ & 9 & 9.2 & $90 \pm 0.03$ & $92 \pm 0.07$ & 4 & 7 & -8 & -8 \\
\hline $\mathbf{5 0}$ & 49 & 48.5 & $98 \pm 0.06$ & $97 \pm 0.07$ & 6 & 7 & -2 & -3 \\
\hline $\mathbf{1 0 0}$ & 102 & 97 & $102 \pm 0.02$ & $97 \pm 0.06$ & 2 & 6 & 2 & -3 \\
\hline $\mathbf{2 0 0}$ & 192 & 196 & $96 \pm 0.01$ & $98 \pm 0.06$ & 1 & 6 & -4 & -2 \\
\hline
\end{tabular}

6 replicates analyzed per each level

Sd: standard deviation,

CV\% (RSD): Coefficient of variation.

\section{Accuracy and precision}

Accuracy expresses the closeness of a result to a true value. Accuracy is expressed in terms of two components: "Trueness" and "Precision". The accuracy of the method was determined by assessing the agreement between the observed and nominal concentrations of analyzed spiked samples ${ }^{[32]}$.

Trueness was checked using 2 certified reference materials (CRM) no. T2772 and T2764 of canned fish by analyzing each of them 6 times, the mean results was compared to the assigned values. Bias and their recoveries with standard deviation were statistically calculated as shown in Table 5. The obtained Bias values were accepted which were less than $2 \%{ }^{[30]}$.

Precision is a measure of how close results are to one another. The two most common precision measures are (repeatability) and (reproducibility). Precision expressed as repeatability was calculated by analyzing each of the four different concentrations levels by six times on the same day, same operator, same reagents and same equipment,. The results of intra-day expressed as repeatability are shown in Table 4. The repeatability relative standard deviation (CV\%) was less than $6 \%$ and $7 \%$ for fish and tuna samples respectively. while the inetr-day reproducibility was assessed over different days by poling the relative standard deviation of repeated determination of the same concentration levels ${ }^{[33]}$. The inter-day assay precision (expressed as polled relative standard deviation RSD \%) was $6 \%$ and $8 \%$ for fish and tuna respectively, these values were considered satisfactory as shown in Table 6.

\section{Measurement uncertainty (MU)}

Uncertainty is a parameter associated with the results of a measurement that characterizes the dispersion of the values that could reasonably be attributed to the measuring. Euachem guidelines were followed to estimate $\mathrm{MU}^{[30]}$. Combined uncertainty (UC) was found to be less than $13 \%$. The following equation is used for combined uncertainty calculations:

$$
U_{C}=\sqrt{\left(U_{p}\right)^{2}+\left(U_{\operatorname{Rec}}\right)^{2}+U_{\operatorname{Re} f}}
$$

Expanded uncertainty is obtained by multiplying the combined uncertainty, by a coverage factor $\mathrm{k}$, for confidence level of $95 \% \mathrm{k}$ is 2 .and it was less than $26.4 \%$.

\section{Application to proficiency scheme}

The method performance was tested using proficiency test to evaluate the compliance with $|\mathrm{Z}|$ score; where $\mathrm{z}$ score $\leq \pm 2$ indicated acceptance. FAPAS round no. 27105 (canned fish) with assigned value $192.6 \mathrm{mg} / \mathrm{kg}$ was analysed and the result was reported as $184 \mathrm{mg} / \mathrm{kg}$ which achieve Z-Score $=-0.6$, this indicated satisfactory results and the developed method could be used successfully in routine analysis.

\section{Application to real fish and canned tuna samples}

In order to demonstrate the applicability of the validated method to routine analysis, thirty four traditional fish and 16 canned tuna samples were obtained from Egyptian local markets during 2009/2010. The validated method was then applied for the detection and determination of Histamine. The maximum tolerance value set by Codex Committee of Food Additives and Contaminants (CCFAC) was used as a point of reference for histamine assessment ${ }^{[10,35]}$.

In a total number of 50 samples, no histamine was detected in 8 samples (6 fish and 2 tuna), while 42 samples (28 fish and 14 tuna) contaminated with histamine. 9 out of 42 contains amount less than the detectable limit (LOQ) while 33 samples had detectable amount with only one sample exceeding the ML levels $(100 \mathrm{ug} / \mathrm{g})$ as shown in Table 7. The amount found in fish (Nile Tilapia, Oreochromis niloticus niloticus)) of $648 \mathrm{ug} / \mathrm{g}$ which is agreed with ${ }^{[36]}$. However, the number of samples is relatively low and should be expanded in other places in Egypt in future studies. The assessment of histamine regularly is important to safeguard people from allergic diseases and control the fish and fish products from bad quality to be ready for export to international markets. 
Table 5: Trueness calculations from analysis of certified reference materials.

\begin{tabular}{|c|c|c|c|c|c|c|c|}
\hline Matrix & $\begin{array}{c}\text { Assigned } \\
(\mathbf{m g} / \mathbf{k g})\end{array}$ & No. & $\begin{array}{c}\text { Mean } \\
(\mathbf{m g} / \mathbf{k g})\end{array}$ & $\begin{array}{c}\text { Mean } \\
\text { Rec \% }\end{array}$ & Sd & Diff & Bias \\
\hline T2772_Canned Fish & 153.0 & 6 & 154.8 & 101.2 & 5.4 & 1.8 & 1.2 \\
\hline T2764_Canned Fish & 26.7 & 6 & 26.2 & 98.1 & 4.7 & 0.5 & 1.9 \\
\hline
\end{tabular}

$\mathrm{Sd}$ : standard deviation, CRM: certified reference material

Bias expressed as absolute relative difference percent (RD \%) must not exceed $20 \%$ and could be calculated using the following equation;

$$
\text { Bias }=\frac{|X-T|}{T} \times 100
$$

Where, $\mathrm{T}$ is the true concentration and $\mathrm{X}$ is the found concentration.

Table 6: Results of reproducibility experiments at four different spiking levels in fish and tuna samples.

\begin{tabular}{|c|c|c|c|c|c|c|c|c|c|c|}
\hline \multirow{2}{*}{ Matrix } & \multicolumn{2}{|c|}{$\begin{array}{c}10 \mathrm{mg} / \mathrm{kg} \\
\mathrm{n}=6\end{array}$} & \multicolumn{2}{|c|}{$\begin{array}{c}50 \mathrm{mg} / \mathrm{kg} \\
\mathrm{n}=6\end{array}$} & \multicolumn{2}{|c|}{$\begin{array}{c}100 \mathrm{mg} / \mathrm{kg} \\
\mathrm{n}=6\end{array}$} & \multicolumn{2}{|c|}{$\begin{array}{c}200 \mathrm{mg} / \mathrm{kg} \\
\mathrm{n}=6\end{array}$} & \multirow{2}{*}{$\begin{array}{c}Q \\
\text { typ }\end{array}$} & \multirow{2}{*}{$\frac{20}{8}$} \\
\hline & $\begin{array}{l}\text { Mean } \\
\text { Rec.\% }\end{array}$ & CV\% & $\begin{array}{l}\text { Mean } \\
\text { Rec.\% }\end{array}$ & $\mathrm{CV} \%$ & $\begin{array}{l}\text { Mean } \\
\text { Rec.\% }\end{array}$ & $\mathrm{CV} \%$ & $\begin{array}{l}\text { Mean } \\
\text { Rec.\% }\end{array}$ & $\mathrm{CV} \%$ & & \\
\hline Fish & 90 & 4 & 98 & 6 & 102 & 2 & 96 & 1 & 96 & 6 \\
\hline Tuna & 92 & 7 & 97 & 7 & 97 & 6 & 98 & 6 & 96 & 8 \\
\hline
\end{tabular}

$\mathrm{n}$ : is no. of replicates,

$\mathrm{CV}_{\text {pooled }}$ : Pooled standard deviation and can be calculated from following equation;

$$
R S D_{\text {pooled }}=\sqrt{\frac{\left(R S D_{1}^{2}\left(n_{1}-1\right)+\left(R S D_{2}^{2}\left(n_{2}-1\right)+\ldots .\right.\right.}{\left(n_{1}-1\right)+\left(n_{2}-1\right)+\ldots .}}
$$

$\mathrm{Q}_{\mathrm{typ}}$ : is the average recovery of the four levels

Table 7: Levels of histamine in $\mathrm{mg} / \mathrm{kg}$ in analyzed fish and canned tuna samples collected from local egyptian markets

\begin{tabular}{|c|c|c|c|c|c|c|c|c|c|c|}
\hline 葛 & 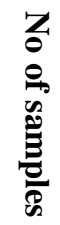 & 总 & 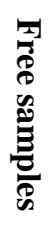 & 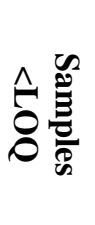 & 当 & 秀 & 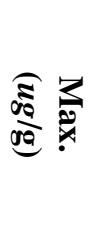 & 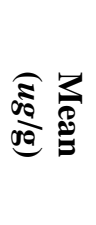 & 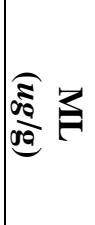 & 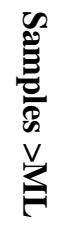 \\
\hline Fish & 34 & 28 & 6 & 9 & 20 & 11.2 & 648 & 48.1 & 100 & 1 \\
\hline Tuna & 16 & 14 & 2 & 0 & 14 & 12 & 92.8 & 28.02 & 200 & - \\
\hline Total & 50 & 42 & 8 & 9 & 34 & & & & & 1 \\
\hline
\end{tabular}
during 2009/2010.

$\mathrm{LOQ}=$ Limit of quantification $(10 u \mathrm{~g} / \mathrm{ml})$

$\mathrm{ML}$; is the maximum permitted limit.

\section{Conclusion}

The optimized method is rapid, reliable and precise that could be applied to monitor histamine in fish and fish products in order to submitt it to local or international markets. The results of monitoring showed that histamine levels in the fish and canned tuna samples were generally acceptable.

\section{References}

1) Lehane, L. and Olley J. (2000). Histamine fish poisoning revisited. Int J Food Microbiol, 58: 1-37.

2) Hungerford, J. M. (2010). Scombroid poisoning: a review. Toxicon., 56(2): 231-243.

3) Mah, J. H., Han, H. K., Oh, Y. J., Kim, M. G. and Hwang, H. J. (2002). Biogenic amines in Jeotkals, 
Korean salted and fermented fish products. Food Chemistry, 79: 239-243.

4) Tassoni, A., Germana, M. A. and Bagni, N. (2004). Free and conjugated polyamine content in Citrus sinensis Osbeck, cultivar brasilino N.L. 92, a Navel orange, at different maturation stages. Food Chemistry, 87: 537-541.

5) Paproski, R. E., Roy, K. I. and Lucy, C. A. (2002). Selective fluorometric detection of polyamines using micellar electrokinetic chromatography with laserinduced fluorescence detection. Journal of Chromatography A, 946: 265-273.

6) U.S Food and Drug Administration (1996). Decomposition and histamine in raw, frozen tuna and mahi-mahi, canned tuna; and related species. Compliance Policy Guides, 7108(240), (Section 540.525).

7) Oguri, S., Enami, M. and Soga, N. (2007). Selective analysis of histamine in food by means of solid-phase extraction cleanup and chromatographic separation. Journal of Chromatography A, 1139: 7074.

8) U.S Food and Drug Administration (2011). Fish and Fishery Products Hazards and Controls Guidance, 4th Ed., Center for Food Safety and Applied Nutrition, Office of Seafood, Washington, DC. Chapter 7, 113.

9) Eurpean Union Directive (2007). Official Journal of European Union. Regulation (EC) No 1441 of 5 December.

10) Codex Alimentarius Commission (190 - 1995). Standard for quick frozen fish fillets, Adopted in 1995. Amendments 2011, 2013, 2014.

11) Lapa, G. and Pickova, J. (2004). New solvent systems for thin-layer chromatographic determination of nine biogenic amines in fish and squid, Journal Chromatography A, 1045(1-2): 22332.

12) Carelli, D., Cetonze, D., Palermo, C., Quinto, M. and Rotunno, T. (2007). An interference free amperometric biosensor for the detection of biogenic amines in food products. Biosens Bioelectron, 23: 640-647.

13) Kvasnicka, F. and Voldrich, M. (2006). Determination of biogenic amines by capillary zone electrophoresis with conductometric detection. Journal of Chromatography A, 1103(1): 145-149.

14) Kalac, P., Svecova, S. and Pelikanova, T. (2002). Levels of biogenic amines in typical vegetable products. Food Chemistry, 77: 349-351.

15) Moret, S., Smela, D., Populin, T. and Conte, L. S. (2005). A survey on free biogenic amine content of fresh and preserved vegetables. Food Chemistry, 89: 355-361.

16) Kirschbaum, J, Rebscher, $K$. and Brückner $H$. (2000). Liquid chromatographic determination of biogenic amines in fermented foods after derivatization with 3, 5-dinitrobenzoyl chloride. Journal of Chromatography A, 881(1-2): 517-530.
17) Oguri, S., Enami, M. and Soga, N. (2007). Selective analysis of histamine in food by means of solid-phase extraction cleanup and chromatographic separation. Journal of Chromatography A, 1139: 70 74.

18) Gosetti, F., Mazzucco, E., Gianotti, V., Polati, S. and Gennaro, M. C. (2007). High performance liquid chromatography/tandem mass spectrometry determination of biogenic amines in typical piedomint cheese, Journal of Chromatography A, 1149:1151-1157.

19) Awan, M. A., Fleet, I., and Thomas, C. L. P. (2008). Determination of biogenic diamines with a vaporisation derivatisation approach using solidphase microextraction gas chromatography-mass spectrometry, Food Chemistry, 111: 462-468.

20) Hwang, D. F., Chang, S. H., Shiau, C. Y. and Chai, T. (1997). High performance liquid chromatographic determination of biogenic amines in fish implicated in food poisoning. Journal of Chromatography B, 693: 23-30.

21) Codex Alimentarius Commission (1993). Portion of Commodities to which Codex Maximum Residue Limits Apply and which is Analysed. Vol. 2, $2^{\text {nd }}$ ed, section A, page 391-404.

22) Penga, J., Fanga, K., Xiea, D., Dinga, B., Yina, J.Y., Cuia, X., Zhanga, Y. and Liub, F. (2008). Development of an automated on-line pre-column derivatization procedure for sensitive determination of histamine in food with high-performance liquid chromatography-fluorescence detection. Journal of Chromatography A, 1209: 70-75.

23) Larionova, D. A., Shtykov, S. N., Beloglazova, N. V. and Koroleva, E. N. (2008). Effect of Nucleophilic Agents and Organized Media on the Fluorimetric Determination of Histamine with $o$ Phthalic Aldehyde Journal of Analytical Chemistry, 63(11): 1044-1050.

24) Saeed, T., Khaksar A. B., Ramin. B. and Mehran, G. (2011). Development and validation of an HPLCFLD method for rapid determination of histamine in skipjack tuna fish (Katsuwonus pelamis), Food Chemistry, 126(2011): 756-761.

25) Sagratini, G., Fernandez-Franzon, M., Berardinis, F., Font, G., Vittori, S. and Manes J. (2012). Simultaneous determination of eight underivatised biogenic amines in fish by solid phase extraction and liquid chromatography-tandem mass spectrometry. Food Chemistry, 132: 537-543.

26) Richard, N. L., Pivarnik, L. F., Christopher, P. E. and Lee C. (2008). Effect of Matrix On Recovery Of Biogenic Amines In Fish. Journal of AOAC International, 91(4): 768-776.

27) Duflos G., Dervin C., Malle P. and Bouquelet S. (1999). Use of Biogenic Amines to Evaluate Spoilage in Plaice (Pleuronectes platessa) and Whiting (Merlangus merlangus). Journal of AOAC International, 82(6): 1357-1393. 
28) Codex Guidelines on Good Laboratory Practice in Residue Analysis (1998). (Alinorm 03/24A) Appendix II, pages 46-79.

29) CITAC/Eurachem Guide (2002). Guide to Quality in Analytical Chemistry, an aid to accreditation.

30) Eurachem guidelines (1998). The Fitness for Purpose of Analytical Methods A Laboratory Guide to Method Validation and Related Topics. Second Edition 2014.

31) Cinquina, A. L., Longo, F., Cal, A., Santis, L., Baccelliere, R. and Cozzani, R.(2004). Validation and comparison of analytical methods for the determination of histamine in tuna fish samples. Journal of Chromatography A, 1032: 79-85.

32) Numanog, l., Hakki, B. and Topcu. (2008). Simple Determination of Histamine in Cheese by Capillary Electrophoresis with Diode Array Detection, Journal of Food and Drug Analysis (JFDA), 16-6-10: 74-80.
33) Saaid, M., Saad, B., Hashim, N., Mohamed Ali, A. and Saleh, M. (2009). Determination of biogenic amines in selected Malaysian food. Food Chemistry, 113: $1356-1362$.

34) Shakila, R. J., Vasundhara, T. S., and Kumudavally, K. V. (2001). A comparison of the TLC-densitometry and HPLCmethod for the determination of biogenic amines in fish and fishery products. Food Chemistry, 75(2): 255-259.

35) Committee of Food Additives and Contaminants. (CCFAC, 1993). Adopted 1995, Revised 1997, 2006, 2008, 2009, Amended 2009.

36) Berjia, F. L. and Brimer L. (2013). Determination of Histamine in Freshwater Fish Using ELISA Method: A Food Safety Concern, American-Eurasian Journal of Toxicological Sciences, 5(4): 94-96. 